\title{
Phosphodiesterase 4-targeted treatments for autoimmune diseases
}

\author{
Neal Kumar ${ }^{*}$, Ari M Goldminz, Noori Kim and Alice B Gottlieb
}

\begin{abstract}
Advancements in phosphodiesterase (PDE)-targeted therapies have shown promise in recent years for treating patients with a variety of autoimmune diseases. This review summarizes the development of PDE4 inhibitors and the associated literature with a focus on treatments for autoimmune diseases. After the initial investigations of the prototypic PDE inhibitor, rolipram, more selective inhibitors targeting the PDE4 isozyme have been developed. With phase II and phase III clinical trials currently underway to evaluate the safety and efficacy of the latest generation of PDE4 inhibitors, namely apremilast, a new class of treatments may be around the corner for patients suffering from chronic, autoimmune diseases.
\end{abstract}

Keywords: Autoimmune, Apremilast, Crohn's, Dermatitis, PDE4, Psoriasis, SLE

\section{Introduction}

Our earliest understanding of phosphodiesterase (PDE) inhibitors began with a series of publications by Sutherland and Rall in the 1950s, describing the properties of cyclic adenosine monophosphate (cAMP). Various cellular pathways and inflammatory responses are mediated by cAMP, an essential intracellular second messenger made up of phosphodiester bonds. Evidence showed formation of cAMP was induced by substances such as epinephrine and glucagon, and the suppression of the enzymes hydrolyzing cAMP, including PDEs, by sodium fluoride and caffeine [1,2]. By the 1960s, the role of cyclic nucleotide second messengers, such as cAMP, in cell signaling and homeostasis was established, and regulation of this pathway by PDE inhibitors arose as a field of considerable interest. However, the immunomodulatory properties of cAMP and the anti-inflammatory potential of PDE inhibitors were not demonstrated until the early 1970s [3-5].

Additional research would later demonstrate the expression of the PDE isoenzyme PDE4 almost exclusively within inflammatory cells [6]. Inhibition of PDE4 leads to the reduction of intracellular cAMP levels, and decreases in $\mathrm{T}$ cell and monocyte derived cytokine and chemokines including tumor necrosis factor (TNF) $\alpha$ [7-11].

\footnotetext{
* Correspondence: neal.kumar@tufts.edu

* Correspondence: neal.kumar@tufts.edu
Department of Dermatology, Tufts Medical Center, 800 Washington Street \#114, Boston, MA 02111, USA
}

Targeting PDE4 has enormous clinical potential because it targets a central pathogenic process that bypasses complex antigen receptor-specific immunoregulatory mechanisms. Indeed, selective PDE4 inhibitors have generated substantial interest as a treatment for several autoimmune conditions including ankylosing spondylitis, Alzheimer's disease, psoriasis, psoriatic arthritis, sarcoidosis, systemic lupus erythematosus, inflammatory bowel disease, atopic dermatitis, rheumatoid arthritis, and multiple sclerosis.

\section{Mechanism of action}

PDEs are a family of enzymes responsible for the hydrolysis and subsequent inactivation of cyclic nucleotides, and have been organized into at least 11 families based on sequence homogeneity, inhibitor sensitivity, and biochemical properties [12].

Each enzyme within the PDE4 family specifically targets cAMP for degradation and consists of four subtypes (PDE4A to PDE4D). These enzymes are located within brain and immunocompetent cells such as neutrophils, T lymphocytes, macrophages and eosinophils [13].

PDE4 inhibition results in the accumulation of the intracellular second messenger cAMP, downstream activation of protein kinase A (PKA), and subsequent phosphorylation of the transcription factor cAMP-response element binding protein (CREB). Activation of this pathway modulates gene transcription of numerous cytokines, and results in suppression of TNF $\alpha$ production 
and eventual inhibition of their proinflammatory and destructive properties [14].

\section{Pharmacokinetics}

The newest and most promising of the PDE4 inhibitors, apremilast, has been evaluated for its pharmacokinetic properties and disposition following oral administration. Multiple daily doses showed rapid absorption $\left(\mathrm{T}_{\max }=\right.$ $2 \mathrm{~h}$ ) and a moderately long half-life (8.2 h) [15].

A separate study monitored healthy male subjects following a single, $20 \mathrm{mg}$, oral dose and found that apremilast was extensively metabolized via multiple pathways, with unchanged drug representing $45 \%$ of the circulating radioactivity and $<7 \%$ of the excreted radioactivity. Analysis of total radioactivity suggests rapid absorption, with plasma $T_{\max }$ values also at $2 \mathrm{~h}$. Mean $\mathrm{C}_{\max }$ and area under the curve (AUC) values in plasma were $333 \mathrm{ng} / \mathrm{ml}$ and $1,970 \mathrm{ng}^{*} \mathrm{~h} / \mathrm{ml}$, respectively. Metabolic clearance of apremilast was the major route of elimination with the key metabolites demonstrating at least 50 -fold less pharmacologic activity than apremilast [16].

Man et al. optimized the structures of a series of 3(1,3-dioxo-1,3-dihydroisoindol-2-yl)-3-(3,4-dialkoxyphenyl) propionic acid analogues to enhance PDE4 and TNFo inhibitory activity. So far, oral and intravenous administration of these analogues in female rats has shown good pharmacokinetics with low clearance, a moderate volume of distribution, and a $64 \%$ oral bioavailability [17].

\section{Adverse effects}

PDE4 is also one of the major phosphodiesterase isoenzymes expressed in the central nervous system, and therefore nausea and emesis are common adverse effects of drug administration [18]. Early PDE4 inhibitors actually failed in clinical trials due to the high prevalence of nausea and emesis [19]. Other adverse effects associated with repeated administration of PDE4 inhibitors include headache, diarrhea, fatigue, dyspepsia, nasopharyngitis, and gastroenteritis [20]. Mesenteric vasculitis is a more worrisome toxicity that may be associated with the PDE4 inhibitors. Studies performed in rodents have demonstrated medial necrosis of the mesenteric arteries after administration of the second generation PDE4 inhibitor cilomilast. However at a meeting convened by the US Food and Drug Administration (FDA) in 2003 to discuss cilomilast in phase III studies, the committee unanimously agreed that the risk of mesenteric vasculitis is not a safety concern based on human studies [21].

The newer PDE4 inhibitor, apremilast, has been well tolerated with few side effects in phase I and II studies. Phase III clinical trials are currently underway and will provide more insight into its dosing and side effect profile. The most frequently reported adverse events have been headache, nausea and pharyngitis $(15,34)$. Researchers used a recognized pharmacophore from the PDE4 inhibitors rolipram and roflumilast in the development of apremilast, and added it to a series of thalidomide analogs in efforts to optimize activity and reduce side effects classically seen with earlier PDE4 inhibitors [22].

\section{Rolipram}

The discovery of the anti-inflammatory actions of PDE4 inhibitors arose from early studies with the prototypic PDE4 inhibitor, rolipram. This was the first selective PDE4 inhibitor investigated, and has been used numerous times for drug comparator studies [23]. Rolipram was also studied as an antidepressant several years before the discovery of its potent PDE4 inhibitory activity $[24,25]$. Despite its potent anti-inflammatory effects in vitro, clinical trials were associated with unacceptably high rates of adverse events, specifically nausea and vomiting [26].

\section{Roflumilast}

Roflumilast was the first, and currently only drug in the PDE4 inhibitor class to be FDA approved. In several countries, this highly selective PDE4 inhibitor is licensed for oral, once-daily treatment of severe chronic obstructive pulmonary disease (COPD). In a pooled analysis of over 6,000 patients receiving roflumilast, higher rates of diarrhea, weight loss, nausea, headache, back pain, insomnia, decreased appetite, and dizziness were reported as compared to those receiving placebo. However the overall rate of adverse events was comparable to that among patients receiving placebo [27].

Pooled results from the pivotal COPD studies M2-124 and M2-125 showed that the weight loss for those in the roflumilast group was generally small $(<3 \%$ of baseline weight) and typically occurred in the first 6 months of treatment. By the end of the 6 months, almost twothirds of the weight loss could be attributed to a reduction in fat mass [28]. Prior investigations have revealed a link between PDE4 and lipolysis, possibly through regulation of cAMP pools in human adipocytes and increased plasma glucagon-like peptide 1 (GLP-1) concentrations in rats $[29,30]$.

\section{Flavonoids}

Many flavonoids have been reported to inhibit PDE4 [31,32], and also demonstrate additional anti-inflammatory effects through other pathways. For example, in addition to PDE4 inhibition, the flavonoid dioclein suppresses the production of the inflammatory mediators interleukin (IL)-6, TNFo, a chemokine ligand (CXCL)1/KC, CCL2/JE (monocyte chemotactic protein 1 ) and nitric oxide (NO), and acts as a scavenger of reactive oxygen species [33]. Studies on dioclein have also demonstrated a synergistic anti-inflammatory effect by targeting multiple pathways [34]. However in contrast to rolipram, dioclein does not 
selectively inhibit PDE4 with additional activity against PDE1, which may lead to unwanted side effects [35].

\section{Psoriasis}

Psoriasis is a chronic inflammatory autoimmune disorder characterized by inflammatory cell infiltration into the dermis and epidermis accompanied by keratinocyte hyperproliferation [36]. Current treatments, including biological therapies, downregulate cytokine cascades and chemokine production. While these interventions can be highly efficacious, limitations include side effects, intravenous or subcutaneous administration, quality control, and production costs.

AN-2728 is a topically administered, boron-containing compound developed for the treatment of psoriasis. This compound was found to reduce cytokine production, such as TNF $\alpha$ and interferon (IFN)y, and demonstrated activity against the PDE4 enzyme [37]. Several clinical trials of AN-2728 have reported significant effects on markers of efficacy, such as TNF $\alpha$, in addition to being well tolerated [38].

The determination of cytokines in skin homogenates revealed that both $\mathrm{T}$ helper (Th)1 as well as Th2 cytokines are suppressed by PDE4 inhibitors, further proving its utility in the treatment of $\mathrm{T}$ cell mediated diseases, such as psoriasis [39].

An open-label, single-arm pilot study investigated the biological and clinical effects of oral apremilast $20 \mathrm{mg}$ once daily in patients with severe plaque-type psoriasis. Of the 19 patients enrolled, 17 completed the study. Of the 19 subjects, 14 (73.7\%) showed improvement in their Psoriasis Area and Severity Index (PASI) scores following a 29-day treatment phase. Among these responders, $\mathrm{T}$ cells were reduced by $28.8 \%$ and $42.6 \%$ in the dermis and epidermis, respectively. Epidermal thickness was also reduced by a mean of $20.5 \%$ from baseline [15].

More recently, a phase IIb, randomized, multicenter, placebo-controlled, dose-ranging trial for the treatment of plaque-type psoriasis with oral apremilast was completed. Patients were randomly assigned to apremilast $10 \mathrm{mg}$ twice daily, apremilast $20 \mathrm{mg}$ twice daily, apremilast $30 \mathrm{mg}$ twice daily, or placebo. By week 16, a $75 \%$ improvement in PASI scores (PASI75) was achieved in 6\% (5/88) assigned placebo, 11\% (10/89) assigned apremilast $10 \mathrm{mg}, 29 \%(25 / 87)$ assigned $20 \mathrm{mg}$, and $41 \%(36 / 88)$ assigned $30 \mathrm{mg}$. Significant differences from placebo were seen with apremilast $20 \mathrm{mg}$ and $30 \mathrm{mg}(P<0.0001)$, but not $10 \mathrm{mg}$. Reported adverse events were most frequently mild to moderate and included nausea, upper respiratory tract infection, diarrhea, nasopharyngitis, headache, gastroenteritis, and dyspepsia. Of the eight serious adverse events, none were judged to be related to apremilast [40].

Currently there are two phase III, double-blind, placebocontrolled, multicenter trials (ESTEEM 1 (NCT01194219) and ESTEEM2 (NCT01232283)) investigating the use of oral apremilast $30 \mathrm{mg}$ in adults with moderate to severe plaque psoriasis. These trials include a 52 week randomized, blinded, placebo-controlled phase, with primary endpoints measured at week 16, in addition to a 4-year extension phase [40].

\section{Psoriatic arthritis}

A phase II, multicenter, randomized, double-blind, placebocontrolled study enrolled 168 subjects with psoriatic arthritis (PsA) during a 12-week treatment phase. Subjects were randomized to $20 \mathrm{mg}$ apremilast twice daily, apremilast $40 \mathrm{mg}$ once daily, or placebo. After completing the initial 12-week phase, subjects receiving placebo were given a 12week course of apremilast. Following the treatment phase in both groups, subjects participated in a 4-week observation phase. The primary endpoint was the proportion of subjects achieving the American College of Rheumatology criteria for 20\% improvement (ACR20) at week 12.

In total, $44 \%$ of actively treated patients achieved the primary endpoint of ACR20 compared with $12 \%$ of the placebo cohort $(P<0.001)$. The study revealed promising results for the treatment of PsA with oral apremilast, but was limited by the relatively short duration and unclear long-term efficacy and safety data. Additionally, the $90 \%$ of subjects enrolled were white and therefore the study may lack generalizability. Lastly, prior systemic therapy for PsA may alter the efficacy of apremilast and was not examined in this study.

The most common adverse events (AEs) were diarrhea, nausea, headache, fatigue, and nasopharyngitis with $84.3 \%$ of subjects in the treatment phase reporting at least one AE. However most events were mild to moderate and no clinically relevant laboratory or electrocardiographic abnormalities were reported [41].

Results of this study are encouraging, and phase III clinical trials are currently underway. The efficacy and tolerability of apremilast in patients with psoriatic arthritis are now being studied in four independent phase III studies (PALACE 1 (NCT01172938), PALACE 2 (NCT01212757), PALACE 3 (NCT01212770), and PALACE 4 (NCT01307423)) [40]. These studies include both patients who have received disease-modifying antirheumatic drugs and those who have not.

\section{Ankylosing spondylitis}

Manifestations of ankylosing spondylitis (AS) include axial and peripheral skeletal inflammation, fat infiltration, and new bone formation. Therapeutic response centers on patient-reported outcomes such as pain, mobility and function as well as objective measures such as inflammation, and new bone formation that can be visualized by magnetic resonance imaging (MRI) and conventional radiography [42-44]. Moreover, the degree of 
clinical response with treatment may also correlate with fluctuations in biomarkers [45-47].

Recently, updated management guidelines published by the Assessment of SpondyloArthritis (ASAS) and the European League Against Rheumatism (EULAR) report that there is no evidence for the efficacy of diseasemodifying antirheumatic drugs (DMARDs) such as methotrexate and sulfasalazine for the treatment of axial disease, leaving patients with limited treatment options. The two classes of drugs that have been shown to reduce the signs and symptoms of AS include non-steroidal antiinflammatory drugs (NSAIDs) and TNF $\alpha$ blockers $[48,49]$.

Nevertheless, at the 2011 ACR meeting, results from a small pilot study were presented showing that apremilast may be efficacious in patients with longstanding AS. This double-blind, placebo controlled phase II unpowered pilot study included 36 subjects with longstanding AS who had not sufficiently responded to NSAIDs over 12 weeks. Of these subjects, 17 received apremilast $30 \mathrm{mg}$ twice daily compared to 19 who received placebo. The apremilast group also saw a significant change from baseline (mean percentage) in levels of receptor activator of nuclear factor $\kappa \mathrm{B}(\mathrm{NF} \kappa \mathrm{B})$ ligand (RANKL) and sclerostin [50].

\section{Rheumatoid arthritis}

Rheumatoid arthritis (RA) is another chronic, inflammatory autoimmune disease and primarily targets the synovial tissues of joints. Local production of cytokines and chemokines leads to leukocyte infiltration, and eventual erosion of cartilage and bone [51,52]. TNF $\alpha$ has been shown to promote cytokine and chemokine production, as well as cellular activation and articular destruction in RA [53].

Given the pathophysiologic characteristics of RA, a study was performed to assess the anti-inflammatory effects of apremilast in human synovial cells collected from rheumatoid arthritis patients, as well as two murine models of arthritis. These synovial cells were cultured in the presence of increasing concentrations of apremilast for $48 \mathrm{~h}$ and enzyme-linked immunosorbent assay (ELISA) was used to analyze spontaneous TNF $\alpha$ production.

Results from this study showed that apremilast led to a dose-dependent inhibition of spontaneous production of TNF $\alpha$ from human rheumatoid synovial membrane cultures. Additionally, both murine models showed a significant reduction in arthritis clinical scores over a ten-day treatment period with apremilast. Healthy joint architecture was also maintained in a dose-dependent manner. Unlike the first generation PDE4 inhibitor rolipram, apremilast did not demonstrate any adverse effects in treatment-naïve mice, possibly due to enhanced selectivity of apremilast [54].

An interim analysis of the data from a phase II pilot study investigating the use of apremilast in combination with methotrexate reported that the primary endpoint of ACR20 was not reached [55]. A placebo-controlled phase II trial using apremilast as monotherapy for RA is currently underway [56].

\section{Systemic lupus erythematosus}

Systemic lupus erythematosus (SLE) is a chronic autoimmune disease that can affect a variety of organs and is predominantly seen in women. Treatment is focused on controlling symptoms and often involves the use of corticosteroids and other systemic immunosuppressant therapies [57,58].

A recent study targeted increased PDE4 activity in lupus conditions using MRL/lpr mice (a mouse model developing severe lupus disease). Four groups of female MRL/lpr mice were injected at 5, 7, 9 and 13 weeks with one of ethanol, pentoxifylline, denbufylline, or NCS 613 (a novel PDE4 inhibitor). Results showed that both the survival time and the appearance of proteinuria of NCS 613-treated mice are significantly delayed, both with $P$ values of 0.005 [59]. While study size was limited, the results demonstrate potential for the use of PDE4 inhibitors in patients with SLE.

\section{Sarcoidosis}

Previous reports have described the use of PDE4 inhibitors in patients with the systemic inflammatory disease, sarcoidosis. While pentoxifylline has been shown to be effective, use of this drug is limited by associated adverse events [60].

A small study evaluated the use of apremilast in 15 subjects who had failed systemic therapies for sarcoidosis. Patients received oral apremilast $20 \mathrm{mg}$ twice daily, with a reduction to once daily dosing following the onset of any adverse event. Only two patients needed dosage reduction due to jitteriness in one patient and nausea in the other. No further adverse events were reported following this change in dose.

Active lesions were assessed during 12 weeks of therapy with the Sarcoidosis Activity and Severity Index (SASI) as well as with photographs taken at baseline and at week 12. Photographs were presented in random order to three assessors and were scored from 1 to 5 (1 much better, 5 much worse).

Results showed a significant reduction in SASI induration scores at weeks 4 and 12 . The normalized mean score given by the assessors after 12 weeks of therapy was $2 / 5$ (somewhat better after therapy), with good interreader consistency. Of note, three patients developed significant worsening of their cutaneous lesions within 3 months after discontinuation of apremilast [61].

\section{Inflammatory bowel disease}

The group of inflammatory conditions affecting the colon and small bowel known as inflammatory bowel disease 
can present in patients with life-altering symptoms lasting weeks to months at a time. Both Crohn's disease and ulcerative colitis (UC) present with diarrhea, bleeding, fecal urgency and incontinence, abdominal pain, and fever caused by inflammation in the gut.

The long-term therapeutic goal for these patients focuses on inducing and maintaining remission of symptoms to improve patient quality of life [62]. Existing antiinflammatory agents such as 5-aminosalicyclates and other immunosuppressants have limitations due to adverse drug reactions, loss of therapeutic response, or lack of response in some patients [63].

Like many autoimmune diseases, the inflammation in inflammatory bowel disease (IBD) has been linked to upregulation of proinflammatory cytokines, such as TNF $\alpha$, and nuclear translocation of the proinflammatory transcription factor complex NFkB [64]. TNF $\alpha$ is thought to damage the gut via upregulation of matrix metalloproteinase (MMP) production by gut myofibroblasts, leading to breakdown of extracellular matrix, tissue damage, and ulcer formation [65]. The quantity of NFKB activation has also been shown to correlate with the degree of mucosal inflammation and disease activity, as well as TNF $\alpha$ upregulation. $\mathrm{NF}_{\kappa} \mathrm{B}$ activation works in a positive feedback to induce $\mathrm{TNF} \alpha$, perpetuating further inflammation and disease processes [66].

Given the suppression of TNF $\alpha$ and $N F \kappa B$ associated with a variety of PDE4 inhibitors, two phase III clinical trials (FACT I and FACT II) were designed. These studies investigated the safety and efficacy of the PDE4 inhibitor, tetomilast, in treating moderately severe UC. Both studies were multicenter, randomized, double-blind, placebo-controlled, parallel-arm, dose comparison studies of tetomilast in subjects with active UC.

Tetomilast was not found to have a significant effect on individual symptom or sigmoidoscopy scores. However, there was a trend for tetomilast to improve severity of rectal bleeding from baseline when compared to placebo $(P=0.017)$. By week 8 , the efficacy scores had improved for those patients receiving tetomilast (with or without concomitant 5-aminosalicylic acid) compared to those on placebo, although these results were not significant statistically. One potential reason for the lack of difference in the therapeutic response may be the very high placebo response rates seen in patients with IBD. Both 25 and $50 \mathrm{mg}$ of tetomilast were generally well tolerated in subjects with active UC with no major adverse events [63].

\section{Atopic dermatitis}

Atopic dermatitis is a chronic inflammatory disease characterized by eczematous lesions and intense itching. Inflammatory infiltrates in these cutaneous lesions consist of T lymphocytes, neutrophils, eosinophils, monocytes, macrophages, and mast cells [67]. High levels of
PDE4 activity are also found in leukocytes of these patients [68].

A study in Japan looked at the effects of PDE4 inhibitors, cilomilast, roflumilast, and rolipram on induced dermatitis in mice models. Cilomilast, roflumilast, and to a lesser extent rolipram, suppressed myeloperoxidase (MPO) activity, a quantitative index of neutrophils accumulating in skin associated with chronic inflammation. After 18 days of treatment, cilomilast and roflumilast showed a 47 and $36 \%$ recovery in skin severity score, respectively. This effect was more potent than the $25 \%$ recovery seen with cyclosporine A, especially in the earlier stages of treatment [69].

A subsequent study by Harada et al. used the PDE4B inhibitor, KF66490 to treat induced AD in mouse models. KF66490 significantly inhibited increases in ear thickness, IL-4 and IL-1B levels, and proliferation of fibroblasts and CD3-positive $\mathrm{T}$ cells. Compared to the first generation PDE4 inhibitor, rolipram, KF66490 also produced less potent emetic effects [70].

More recently, an open-label prospective trial of apremilast in 16 patients with moderate to severe $\mathrm{AD}$ was conducted to assess the safety, efficacy, and possible mechanism of action of apremilast in AD. One cohort consisted of six subjects treated with apremilast $20 \mathrm{mg}$ twice daily for 3 months, while the second cohort consisted of ten subjects treated with apremilast $30 \mathrm{mg}$ twice daily for 6 months. Participants in the study were required to remain on triamcinolone acetonide $0.1 \%$ for 2 weeks prior to the start of the study as well as throughout the trial. Nausea, the most common adverse event, was rated as mild and improved over the course of the study in all patients. After 3 months of treatment, a significant reduction of itch from baseline (VAS) and improvement in quality of life (assessed via Dermatology Life Quality Index (DLQI) score) was seen in cohort 1 ( $P=0.02$ and $P=0.003$, respectively), while Eczema Area and Severity Index (EASI) and quality of life (DLQI) scores improved in cohort $2(P=0.008$ and $P=0.01$, respectively). At 6 months, statistically significant improvement was seen in all outcomes in cohort 2, including VAS $(P=0.03)$, DLQI $(P=0.03)$, and EASI $(P=0.002)[71]$.

\section{Alzheimer's disease}

PDE4 inhibitors have also been investigated in the treatment of patients with Alzheimer's disease. The neuropathological changes seen in Alzheimer's are closely linked to chronic inflammation and apoptosis, with elevations of biomarkers seen even in early stages of disease [72].

Accumulation of amyloid beta $(A \beta)$ peptides has been shown to produce inflammatory responses [73], activate the apoptotic pathway [74], inhibit hippocampal synaptic plasticity, and impair memory [75]. Similar responses were induced by infusion of aged Ab25-35 into the 
hippocampus, with reversal of memory deficits seen following repeated treatment with rolipram. These positive findings may be at least partially attributed to the blockade of inflammatory responses and apoptosis mediated by $\mathrm{CAMP} / \mathrm{CREB}$ signaling. In fact, increased levels of PCREB were reported in the hippocampus following treatment with rolipram. These results may suggest a potential role for the use of PDE4 inhibitors in treatment of memory loss in patients with Alzheimer's [75].

\section{Multiple sclerosis}

The demyelinating autoimmune disease, multiple sclerosis (MS), has often been studied in animal models by inducing experimental autoimmune encephalomyelitis (EAE) in genetically susceptible animals [76]. The EAE model also mimics the relapsing-remitting presentation of MS seen in humans.

One study demonstrated a reduction in the clinical signs of EAE in mice models during the administration of rolipram. Improvement was seen during both the initial presentation of disease as well as subsequent relapses [77].

Matrix metalloproteinases (MMPs) are a gene family of zinc-dependent endopeptidases involved in the proteolytic modeling of the extracellular matrix as well as the pathogenesis of several autoimmune disorders of the peripheral and central nervous systems, such as MS [78]. In vitro models have shown that rolipram inhibits $\mathrm{NFKB}$, a key regulator of inflammatory processes and gene expression related to EAE and MS, including MMP-9 [79].

When rats primed to EAE were treated with rolipram, the high levels of $\mathrm{NFK}_{\mathrm{B}} \mathrm{B}$ activation in freshly obtained cells were prevented. Furthermore, inhibition was also seen after incubation of encephalitogenic cells with rolipram, indicating that interference with $\mathrm{NFKB}$ activation is a direct effect of the drug. Inhibition of $\mathrm{NF \kappa B}$ was also accompanied by a decrease in MMP-9 gene expression [80].

\section{Conclusions}

Advancements in phosphodiesterase-targeted therapies have shown promise in recent years for treating patients with a variety of autoimmune diseases. After the initial investigations of the prototypic PDE inhibitor rolipram, more selective inhibitors targeting the PDE4 isozyme have been developed. With phase II and phase III clinical trials currently underway to evaluate the safety and efficacy of the latest generation of PDE4 inhibitors, namely apremilast, a new class of treatments may be around the corner for patients suffering from chronic, autoimmune diseases.

\section{Abbreviations}

Aß: Amyloid beta; ACR20: American college of rheumatology criteria for 20\% improvement; AE: Adverse event; AS: Ankylosing spondylitis; ASAS: Assessment of spondyloarthritis; CAMP: Cyclic adenosine monophosphate; CREB: CAMP-response element binding protein; COPD: Chronic obstructive pulmonary disease; $\mathrm{CXCL}$ : Chemokine $\mathrm{C}-\mathrm{X}-\mathrm{C}$ motif ligand; DLQI: Dermatology life quality index; DMARD: Disease-modifying antirheumatic drug; EAE: Experimental autoimmune encephalomyelitis; EASI: Eczema area and severity index; ELISA: Enzyme-linked immunosorbent assay; EULAR: European League Against Rheumatism; GLP-1: Glucagon-like peptide; IFN: Interferon; IL: Interleukin; MMP: Matrix metalloproteinase; MPO: Myeloperoxidase; MS: Multiple sclerosis; NFKB: Nuclear factor KB; NO: Nitric oxide; NSAID: Non-steroidal anti-inflammatory drug; PASI: Psoriasis area and severity index; PDE: Phosphodiesterase; PKA: Protein kinase A; PSA: Psoriatic arthritis; RA: Rheumatoid arthritis; RANKL: Receptor activator of NFKB ligand; SASI: Sarcoidosis activity and severity index; SLE: Systemic lupus erythematosus; TNF: Tumor necrosis factor; UC: Ulcerative colitis; VAS: Visual analog scale.

\section{Competing interests}

ABG is on the advisory boards of Abbott Laboratories, Actelion, Amgen, Astellas Pharma US Inc., Belersdorf Inc., BMS, Celgene Corporation, Coronado Biosciences, Janssen-Ortho Inc., Novo Nordisk A/S, Pfizer Inc., and UCB. ABG is a consultant to Abbott Laboratories, Amgen, Canfite, Celgene Corporation, Incyte Corporation, Lilly ICOS LLC, Merck \& Co. Inc., Novartis Pharmaceuticals Corp., and Teva. ABG holds an investigator role for Abbott Laboratories, Celgene Corporation, Immune Control, Janssen-Ortho Inc., Lilly ICOS LLC, Novartis Pharmaceuticals Corp., Novo Nordisk A/S, Pfizer Inc., and UCB. ABG has received an institutional grant from Amgen, and honoraria from DermiPsor. NKu, AMG and NKi have no competing interests.

\section{Authors' contributions}

All authors made substantial contributions to the drafting, reading and editing, and approved the final manuscript.

Received: 21 September 2012 Accepted: 11 February 2013 Published: 4 April 2013

\section{References}

1. Sutherland EW, Rall T: The properties of an adenine ribonucleotide produced with cellular particles, ATP, mg, and epinephrine or glucagon. J Am Chem Soc 1957, 79:3608-3608

2. Rall T, Sutherland E: Fractionation and characterization of a cyclic adenine ribonucleotide formed by tissue particles. J Biol Chem 1958, 232:1077.

3. Henney CS, Lichtenstein LM: The role of cyclic AMP in the cytolytic activity of lymphocytes. J Immunol 1971, 107:610-612.

4. Henney CS, Bourne HR, Lichtenstein LM: The role of cyclic 3', 5' adenosine monophosphate in the specific cytolytic activity of lymphocytes. J Immunol 1972, 108:1526.

5. Bourne H, Weinstein Y, Melmon K, Lichtenstein L, Henney C, Shearer G: Modulation of inflammation and immunity by cyclic AMP. Science 1974, 184:19-28.

6. Essayan DM: Cyclic nucleotide phosphodiesterase (PDE) inhibitors and immunomodulation. Biochem Pharmacol 1999, 57:965-973.

7. Giembycz MA, Corrigan C, Seybold J, Newton R, Barnes P: Identification of cyclic AMP phosphodiesterases 3, 4 and 7 in human CD4 and CD8 Tlymphocytes: role in regulating proliferation and the biosynthesis of interleukin-2. Br J Pharmacol 1945, 1996:118.

8. Manning CD, Burman M, Christensen SB, Cieslinski LB, Essayan DM, Grous M, Torphy TJ, Barnette MS: Suppression of human inflammatory cell function by subtype-selective PDE4 inhibitors correlates with inhibition of PDE4A and PDE4B. Br J Pharmacol 1999, 128:1393-1398.

9. Hidi R, Timmermans S, Liu E, Schudt C, Dent G, Holgate ST, Djukanović R: Phosphodiesterase and cyclic adenosine monophosphate-dependent inhibition of T-lymphocyte chemotaxis. Eur Respir J 2000, 15:342-349.

10. Brideau C, Van Staden C, Styhler A, Rodger IW, Chan CC: The effects of phosphodiesterase type 4 inhibitors on tumour necrosis factor.alpha; and leukotriene B4 in a novel human whole blood assay. $\mathrm{Br} J$ Pharmacol 1999, 126:979-988.

11. Gale DD, Landells LJ, Spina D, Miller AJ, Smith K, Nichols T, Rotshteyn Y, Tonelli A, Lacouture P, Burch RM, Page CP, O'Connor BJ: Pharmacokinetic and pharmacodynamic profile following oral administration of the phosphodiesterase (PDE) 4 inhibitor V11294A in healthy volunteers. Br J Clin Pharmacol 2002, 54:478-484.

12. Lipworth BJ: Phosphodiesterase- 4 inhibitors for asthma and chronic obstructive pulmonary disease. Lancet 2005, 365:167-175. 
13. Pieretti S, Dominici L, Di Giannuario A, Cesari N, Dal Piaz V: Local antiinflammatory effect and behavioral studies on new PDE4 inhibitors. Life Sci 2006, 79:791-800

14. Spina D: PDE4 inhibitors: current status. Br J Pharmacol 2008, 155:308-315.

15. Gottlieb A, Strober B, Krueger J, Rohane P, Zeldis JB, Hu CC, Kipnis C: An open-label, single-arm pilot study in patients with severe plaque-type psoriasis treated with an oral anti-inflammatory agent, apremilast* . Curr Med Res Opin 2008, 24:1529-1538.

16. Hoffmann M, Kumar G, Schafer P, Cedzik D, Capone L, Fong KL, Gu Z, Heller D, Feng $H$, Surapaneni S, Laskin O, Wu A: Disposition, metabolism and mass balance of [14C] apremilast following oral administration. Xenobiotica 2011, 41:1063-1075.

17. Man HW, Schafer P, Wong LM, Patterson RT, Corral LG, Raymon H, Blease K, Leisten J, Shirley MA, Tang Y, Babusis DM, Chen R, Stirling D, Muller GW: Discovery of (S)-N-\{2-[1-(3-ethoxy-4-methoxyphenyl)-2methanesulfonylethyl]-1, 3-dioxo-2, 3-dihydro-1 H-isoindol-4-yl\} acetamide (apremilast), a potent and orally active phosphodiesterase 4 and tumor necrosis factor-a inhibitor. J Med Chem 2009, 52:1522-1524.

18. Giembycz MA: Phosphodiesterase 4 inhibitors and the treatment of asthma: where are we now and where do we go from here? Drugs 2000, 59:193-212.

19. Dyke H, Montana J: Update on the therapeutic potential of PDE4 inhibitors. Expert Opin Investig Drugs 2002, 11:1.

20. Dietsch GN, Dipalma CR, Eyre RJ, Pham TQ, Poole KM, Pefaur NB, Welch WD, Trueblood E, Kerns WD, Kanaly ST, Stirling D, Muller GW: Characterization of the inflammatory response to a highly selective PDE4 inhibitor in the rat and the identification of biomarkers that correlate with toxicity. Toxicol Pathol 2006, 34:39-51.

21. GlaxoSmithKline: SB 207499 (ariflo, cilomilast) [9 February 2006]. New drugs application (21-573), Pulmonary and allergy drug products advisory committee. Nonclinical findings. 2003. http://www.fda.gov/ohrms/dockets/ ac/03/transcripts/3976T1.doc.

22. Man HW, Schafer $P$, Wong LM, Patterson RT, Corral LG, Raymon H, Tang $Y$ : Discovery of (S)-N-\{2-[1-(3-ethoxy-4-methoxyphenyl)-2methanesulfonylethyl]-1, 3-dioxo-2, 3-dihydro-1 H-isoindol-4-yl\} acetamide (apremilast), a potent and orally active phosphodiesterase 4 and tumor necrosis factor-a inhibitor. J Med Chem 2009, 52:1522-1524.

23. Christensen SB, Guider A, Forster CJ, Gleason JG, Bender PE, Karpinski JM, DeWolf WE Jr, Barnette MS, Underwood DC, Griswold DE, Cieslinski LB, Burman M, Bochnowicz S, Osborn RR, Manning CD, Grous M, Hillegas LM, Bartus JO, Ryan MD, Eggleston DS, Haltiwanger RC, Torphy TJ: 1, 4cyclohexanecarboxylates: potent and selective inhibitors of phosophodiesterase 4 for the treatment of asthma. J Med Chem 1998, 41:821-835

24. Wachtel $\mathrm{H}$ : Potential antidepressant activity of rolipram and other selective cyclic adenosine $3^{\prime}, 5^{\prime}$-monophosphate phosphodiesterase inhibitors. Neuropharmacology 1983, 22:267-272.

25. Davis CW: Assessment of selective inhibition of rat cerebral cortical calcium-independent and calcium-dependent phosphodiesterases in crude extracts using deoxycyclic AMP and potassium ions. Biochim Biophys Acta 1984, 797:354-362.

26. O'Donnell JM, Zhang HT: Antidepressant effects of inhibitors of CAMP phosphodiesterase (PDE4). Trends Pharmacol Sci 2004, 25:158-163.

27. Calverley PMA, Fabbri LM, Rabe KF, Mosberg H: Roflumilast in the treatment of COPD: a pooled safety analysis. Eur Respir J 2010. Abstract P4001.

28. Calverley P, Rabe KF, Goehring UM, Kristiansen S, Fabbri LM, Martinez FJ: Roflumilast in symptomatic chronic obstructive pulmonary disease: two randomised clinical trials. Lancet 2009, 374:685.

29. Omar B, Zmuda-Trzebiatowska E, Manganiello V, Goransson O, Degerman E: Regulation of AMP-activated protein kinase by CAMP in adipocytes: roles for phosphodiesterases, protein kinase B, protein kinase A, Epac and lipolysis. Cell Signal 2009, 21:760-766.

30. Ong WK, Gribble FM, Reimann F, Lynch MJ, Houslay MD, Baillie GS, Furman $B L$, Pyne NJ: The role of the PDE4D cAMP phosphodiesterase in the regulation of glucagon-like peptide-1 release. $\mathrm{Br}$ J Pharmacol 2009 157:633-644.

31. Middleton E Jr, Kandaswami C, Theoharides TC: The effects of plant flavonoids on mammalian cells: implications for inflammation, heart disease, and cancer. Pharmacol Rev 2000, 52:673-751.
32. Peluso MR: Flavonoids attenuate cardiovascular disease, inhibit phosphodiesterase, and modulate lipid homeostasis in adipose tissue and liver. Exp Biol Med 2006, 231:1287-1299.

33. Guabiraba R, Campanha-Rodrigues AL, Souza ALS, Santiago HC, Lugnier C, Alvarez-Leite J, Lemos VS, Teixeira MM: The flavonoid dioclein reduces the production of pro-inflammatory mediators in vitro by inhibiting PDE4 activity and scavenging reactive oxygen species. Eur J Pharmacol 2010 633:85-92.

34. Ribeiro $S$, Horuk R: The clinical potential of chemokine receptor antagonists. Pharmacol Ther 2005, 107:44-58.

35. Gonçalves RL, Lugnier C, Keravis T, Lopes MJ, Fantini FA, Schmitt M, Cortes SF, Lemos VS: The flavonoid dioclein is a selective inhibitor of cyclic nucleotide phosphodiesterase type 1 (PDE1) and a cGMP-dependent protein kinase (PKG) vasorelaxant in human vascular tissue. Eur J Pharmacol 2009, 620:78-83.

36. Lowes MA, Bowcock AM, Krueger JG: Pathogenesis and therapy of psoriasis. Nature 2007, 445:866-873.

37. Akama T, Baker SJ, Zhang YK, Hernandez V, Zhou H, Sanders V, Freund Y, Kimura R, Maples KR, Plattner JJ: Discovery and structure-activity study of a novel benzoxaborole anti-inflammatory agent (AN2728) for the potential topical treatment of psoriasis and atopic dermatitis. Bioorg Med Chem Lett 2009, 19:2129-2132.

38. Nazarian $\mathrm{R}$, Weinberg JM: AN-2728, a PDE4 inhibitor for the potential topical treatment of psoriasis and atopic dermatitis. Curr Opin Investig Drugs 2009, 10:1236-1242.

39. Baumer W, Hoppmann J, Rundfeldt C, Kietzmann M: Highly selective phosphodiesterase 4 inhibitors for the treatment of allergic skin diseases and psoriasis. Inflamm Allergy Drug Targets 2007, 6:17-26.

40. Papp K, Cather JC, Rosoph L, Sofen H, Langley RG, Matheson RT, Hu C, Day RM: Efficacy of apremilast in the treatment of moderate to severe psoriasis: a randomised controlled trial. Lancet 2012, 380:738-746.

41. Schett G, Wollenhaupt J, Papp K, Joos R, Rodrigues JF, Vessey AR, Hu C, Stevens $\mathrm{R}$, de Vlam KL: Oral apremilast in the treatment of active psoriatic arthritis: results of a multicenter, randomized, double-blind, placebocontrolled study. Arthritis Rheum 2012, 64:3156-3167.

42. Baraliakos $X$, Hermann KG, Braun J: Imaging in axial spondyloarthritis: diagnostic problems and pitfalls. Rheum Dis Clin North Am 2012, 38:513-522.

43. Baraliakos $X$, Listing J, Rudwaleit M, Sieper J, Braun J: The relationship between inflammation and new bone formation in patients with ankylosing spondylitis. Arthritis Res Ther 2010, 10:104.

44. Chiowchanwisawakit P, Lambert RGW, Conner-Spady B, Maksymowych WP Focal fat lesions at vertebral corners on magnetic resonance imaging predict the development of new syndesmophytes in ankylosing spondylitis. Arthritis Rheum 2011, 63:2215-2225.

45. Machado P, Landewé R, Lie E, Kvien TK, Braun J, Baker D, van der Heijde D: Ankylosing spondylitis disease activity score (ASDAS): defining cut-off values for disease activity states and improvement scores. Ann Rheum Dis 2011, 70:47-53.

46. Visvanathan S, Wagner C, Marini J, Baker D, Gathany T, Han J, van der Heijde D, Braun J: Inflammatory biomarkers, disease activity and spinal disease measures in patients with ankylosing spondylitis after treatment with infliximab. Ann Rheum Dis 2008, 67:511-517

47. Visvanathan S, van der Heijde D, Deodhar A, Wagner C, Baker DG, Han J, Braun J: Effects of infliximab on markers of inflammation and bone turnover and associations with bone mineral density in patients with ankylosing spondylitis. Ann Rheum Dis 2009, 68:175-182.

48. Braun J, Van den Berg R, Baraliakos X, Boehm H, Burgos-Vargas R, CollantesEstevez E, Dagfinrud H, Dijkmans B, Dougados M, Emery P, Geher P, Hammoudeh M, Inman RD, Jongkees M, Khan MA, Kiltz U, Kvien T, LeirisaloRepo M, Maksymowych WP, Olivieri I, Pavelka K, Sieper J, StanislawskaBiernat E, Wendling D, Ozgocmen S, van Drogen C, van Royen B, van der Heijde D: 2010 update of the ASAS/EULAR recommendations for the management of ankylosing spondylitis. Ann Rheum Dis 2011, 70:896.

49. van der Heijde D, Sieper J, Maksymowych WP, Dougados M, Burgos-Vargas R, Landewé R, Rudwaleit M, Braun J: 2010 update of the international ASAS recommendations for the use of anti-TNF agents in patients with axial spondyloarthritis. Ann Rheum Dis 2011, 70:905-908.

50. Pathan E, Abraham S, Van-Rossen L: Efficacy and safety of apremilast, an oral phosphodiesterase 4 inhibitor, in ankylosing spondylitis. Ann Rheum Dis. In press. 
51. Brennan FM, Jackson A, Chantry D, Maini R, Feldmann M: Inhibitory effect of TNFa antibodies on synovial cell interleukin-1 production in rheumatoid arthritis. Lancet 1989, 334:244-247.

52. Feldmann M, Maini RN: TNF defined as a therapeutic target for rheumatoid arthritis and other autoimmune diseases. Nat Med 2003, 9:1245-1250.

53. Sekut L, Yarnall D, Stimpson S, Noel LS, Bateman-Fite R, Clark RL, Brackeen MF, Menius JA Jr, Connolly KM: Anti-inflammatory activity of phosphodiesterase (PDE)-IV inhibitors in acute and chronic models of inflammation. Clin Exp Immunol 1995, 100:126-132.

54. McCann FE, Palfreeman AC, Andrews M, Perocheau DP, Inglis JJ, Schafer $P$, Feldmann M, Williams RO, Brennan FM: Apremilast, a novel PDE4 inhibitor, inhibits spontaneous production of tumour necrosis factor-alpha from human rheumatoid synovial cells and ameliorates experimental arthritis. Arthritis Res Ther 2010, 12:R107.

55. Schett $G$, Wollenhaupt J, Papp K: Apremilast is active in the treatment of rheumatoid arthritis [abstract 1258]. Arthritis Rheum 2009, 60:S10.

56. Cush J, Research Institute: The controlled trial of Apremilast for rheumatoid arthritis treatment. http://clinicaltrials.gov/show/NCT01250548.

57. Rahman A, Isenberg DA: Systemic lupus erythematosus. N Engl J Med 2008, 358:929-939.

58. Monneaux F, Muller S: Molecular therapies for systemic lupus erythematosus: clinical trials and future prospects. Arthritis Res Ther 2010, 11:234.

59. Keravis T, Monneaux F, Yougbaré I, Gazi L, Bourguignon JJ, Muller S, Lugnier C: Disease progression in MRL/lpr lupus-prone mice is reduced by NCS 613 , a specific cyclic nucleotide phosphodiesterase type 4 (PDE4) inhibitor. PLoS One 2012, 7:e28899.

60. Park M, Fontana J, Babaali H, Gilbert-McClain LI, Stylianou M, Joo J, Moss J, Manganiello VC: Steroid-sparing effects of pentoxifylline in pulmonary sarcoidosis. Sarcoidosis Vasc Diffuse lung Dis 2009, 26:121.

61. Baughman RP, Judson MA, Ingledue R, Craft NL, Lower EE: Efficacy and safety of apremilast in chronic cutaneous sarcoidosis. Arch Dermatol 2012, 148:262-264.

62. Podolsky DK: Inflammatory bowel disease. N Engl J Med 2002, 347:417-429.

63. Keshavarzian A, Mutlu E, Guzman JP, Forsyth C, Banan A: Phosphodiesterase 4 inhibitors and inflammatory bowel disease: emerging therapies in inflammatory bowel disease. Exp Opin Invest Drugs 2007, 16:1489-1506.

64. Hollander D: Crohn's disease-a permeability disorder of the tight junction? Gut 1988, 29:1621-1624.

65. Gordon J, Prothero J, Thornton C, Pickard KM, Di Sabatino A, Goggin PM, Pender SL, Macdonald TT: CC-10004 but not thalidomide or lenalidomide inhibits lamina propria mononuclear cell TNF-

.alpha; and MMP-3 production in patients with inflammatory bowel disease. J Crohns Colitis 2009, 3:175-182.

66. Schreiber S, Nikolaus S, Hampe J: Activation of nuclear factor $\mathrm{kB}$ in inflammatory bowel disease. Gut 1998, 42:477-484.

67. Cooper KD: Atopic dermatitis: recent trends in pathogenesis and therapy. J Invest Dermatol 1994, 102:128-137.

68. Butler JM, Chan SC, Stevens S, Hanifin JM: Increased leukocyte histamine release with elevated cyclic AMP-phosphodiesterase activity in atopic dermatitis. J Allergy Clin Immunol 1983, 71:490-497.

69. Harada D, Ikeda Y, Nosaka Y, Kobayashi K, Manabe H: Curative effects of phosphodiesterase 4 inhibitors cilomilast, roflumilast, and rolipram in dermatitis mouse model. J Dermatol Sci 2008, 51:215-219.

70. Harada D, Takada C, Nosaka Y, Takashima Y, Kobayashi K, Takaba K, Manabe H: Effect of orally administered KF66490, a phosphodiesterase 4 inhibitor, on dermatitis in mouse models. Int Immunopharmacol 2009, 9:55-62.

71. Samrao A, Berry TM, Goreshi R, Simpson EL: A pilot study of an oral phosphodiesterase inhibitor (apremilast) for atopic dermatitis in adults. Arch Dermatol 2012, 812:v1.

72. Luterman JD, Haroutunian V, Yemul S, Ho L, Purohit D, Aisen PS, Mohs R, Pasinetti GM: Cytokine gene expression as a function of the clinical progression of alzheimer disease dementia. Arch Neurol 2000, 57:1153.

73. Abdi A, Sadraie H, Dargahi L, Khalaj L, Ahmadiani A: Apoptosis inhibition can be threatening in $A \beta$-induced neuroinflammation, through promoting cell proliferation. Neurochem Res 2011, 36:39-48.

74. Mattson MP: Pathways towards and away from alzheimer's disease. Nature 2004, 430:631-639.
75. Wang C, Yang XM, Zhuo YY, Zhou H, Lin HB, Cheng YF, Xu JP, Zhang HT: The phosphodiesterase- 4 inhibitor rolipram reverses $A \beta$-induced cognitive impairment and neuroinflammatory and apoptotic responses in rats. Int J Neuropsychopharmacol 2011, 1:1-18.

76. Khoruts A, Miller SD, Jenkins MK: Neuroantigen-specific Th2 cells are inefficient suppressors of experimental autoimmune encephalomyelitis induced by effector Th1 cells. J Immunol 1995, 155:5011.

77. Sommer N, Martin R, McFarland H, Quigley L, Cannella B, Raine CS, Scott DE, Löschmann PA, Racke MK: Therapeutic potential of phosphodiesterase type 4 inhibition in chronic autoimmune demyelinating disease. J Neuroimmunol 1997, 79:54-61.

78. Hartung HP, Kieseier BC: The role of matrix metalloproteinases in autoimmune damage to the central and peripheral nervous system. J Neuroimmunol 2000, 107:140-147.

79. Kieseier BC, Kiefer R, Clements JM, Miller K, Wells GM, Schweitzer T, Gearing AJ, Hartung HP: Matrix metalloproteinase- 9 and-7 are regulated in experimental autoimmune encephalomyelitis. Brain 1998, 121:159-166.

80. Sánchez AJ, Puerta C, Ballester S, González P, Arriaga A: Rolipram impairs NF-KB activity and MMP-9 expression in experimental autoimmune encephalomyelitis. J Neuroimmunol 2005, 168:13-20.

\section{doi:10.1186/1741-7015-11-96}

Cite this article as: Kumar et al:: Phosphodiesterase 4-targeted

treatments for autoimmune diseases. BMC Medicine 2013 11:96.

\section{Submit your next manuscript to BioMed Central and take full advantage of:}

- Convenient online submission

- Thorough peer review

- No space constraints or color figure charges

- Immediate publication on acceptance

- Inclusion in PubMed, CAS, Scopus and Google Scholar

- Research which is freely available for redistribution 